\title{
Transitional Experiences of Chinese Students to Graduate Study at a Canadian University Within a Social, Political, Cultural, and Linguistic Context*
}

\author{
Noel Hurley, Hailiang Zhao, Peng Yu, Dandan Lu, Xin Wang \\ Memorial University of Newfoundland, St. John's, Canada
}

\begin{abstract}
The transition from one ancient Asian culture to a very different Western culture is pursued here from the perspective of four graduate students from China. Each graduate student came from very different backgrounds and circumstances yet the transition adjustments were similar for all. The main pursuit of this paper was to identify factors that ease transitions and factors that make transitions more difficult. Age, gender, work experience, academic preparation, and linguistic proficiency were different for each writer and these demographic effects seemed to cause different levels of comfort in their adjustment to their new surroundings. The paper used a narrative approach to qualitatively draw comparisons among the four graduate participants. Findings are hopefully to be helpful in preparing future students experience easier transitions as they move from China to study in Western universities. The following research questions were asked: 1 . Why did you apply to study in Canada? 2 . Where else did you apply? 3. What was the biggest difficulty you experienced in coming here? 4 . How prepared were you to come to Canada from a linguistic, social, cultural, political, and financial perspective? 5. How accommodating and helpful were university officials? Government officials? Others? 6. Did anyone serve as a liaison during your move here? 7. Do you feel that your transition has been successful? 8. What or who has helped you most during your transition? 9. Are costs to come and study here too prohibitive for most Chinese university graduates? 10. Has the cultural, social, linguistic, political, and economic differences been more or less than you expected? You might like to examine each of these aspects individually. 11. What has been your greatest help? 12. What has been your greatest hindrance? 13. What has been your most pleasant surprise? 14. What has been your biggest disappointment? 15. What should the university do to make the transition of students from China easier? and 16. What would you recommend to other Chinese university graduates to do before coming to Canada?
\end{abstract}

Keywords: cultural transition, graduate preparation, pre-requisite linguistic ability, socio-cultural adaptation

\section{Introduction}

Suzuki and Taylor (2009) said that just a short time ago, not many of us travelled more than 100 miles

\footnotetext{
${ }^{*}$ A paper presented to the Conference on Envisioning Reciprocal Learning Between Canada and China, University of Windsor, Windsor, Ontario, April 7-8, 2014.

Noel Hurley, Ph.D., associate professor, Faculty of Education, Memorial University of Newfoundland.

Hailiang Zhao, post-graduate student, Faculty of Education, Memorial University of Newfoundland.

Peng Yu, post-graduate student, Faculty of Education, Memorial University of Newfoundland.

Dandan Lu, Ph.D. candidate, Faculty of Education, Memorial University of Newfoundland.

Xin Wang, post-graduate student, Faculty of Education, Memorial University of Newfoundland.
} 
from where we were born. They went on to state that we have come so far in such a short period of time that it is mind-boggling. This Conference on Envisioning Reciprocal Learning Between Canada and China is evidence of the globalized activities that we are undergoing every day. The baby-boomer generation was perhaps the first cohort that had to compete internationally within graduate programs within our universities. The competition that we faced was usually not for admission but for class ranking and status when being compared with holders of international scholarships, such as the Commonwealth Scholarships and the like. Admission to graduate programs now sees our domestic students having to compete for academic seats against students from all over the world. After graduation, our graduates are in a similar way competing for the best jobs in a global market.

In academic settings, we sink or swim based on our success in obtaining grants, producing research papers, and getting them published. This paradigm should fast become outmoded as we seek to share knowledge and information in an open resource learning model. In most market economies, knowledge is seen as power which in turn translates to money. Expectations have long created and decimated wealth on massive scales in the world's stock markets and we can expect that market-driven forces will resist open resource sharing with the underdeveloped and developing economies of the world. This is clearly seen in the unwillingness of large pharmaceuticals to share life-saving drugs until after their patents have expired.

Our developed countries continue to pursue the brightest minds to work in research and graduate studies from countries all over the world. This brain-drain has been a constant for the past century in a manner that is openly competitive. The practice had its beginning back in ancient times when emperors brought creative artists and thinkers back to Rome and other ancient cities. We continue the practice to this day and to that effect, we want to share the transitions of four of these bright students that we have attracted from China to Eastern Canada. If we add to their human capital value by mentoring them to successfully obtain their respective graduate degrees and if they stay here in Canada to work, then we will have benefitted from the prior investment made in their education by China. If on the other hand they return to China, then it is likely that China will benefit from our investment. The benefit flows in this sector have historically favoured the more developed countries as they have been able to offer the more attractive working conditions.

This conference has afforded an opportunity to promote research writing and skills for several of the first author's graduate students. The graduate program at Memorial University of Newfoundland (MUN) usually has about 900 students registered each semester and many are international students. Four current Chinese graduate students from our leadership program are recounting their transitional experiences thus far as they continue their adjustment to life in Canada's Happy Province. Two of the students are male and two are female. The two male students and one female student have extensive experience working at varying levels of the Chinese school system. The youngest student is the least experienced in the educational system and she begins a new program of study next month. The ages are $24,33,40$, and 44 with the females being younger. All of these students are independent learners who are risk-takers and who possess confidence in their learning abilities. Even the best communicators found that they faced linguistic challenges as they began their studies in a new English setting.

Hurley (2002) provided evidence that Bernstein's Theory of Language Discontinuity had validity in predicting how language mediates one's learning. Bernstein had posited that, in every society, there is a standard language code; for example, in England that could be stated as the Queen's own manner of speaking. He theorized that the further a learner differed from this standard language code, then the harder it was for that 
person to learn. Hurley was able to predict up to $90 \%$ of reading scores in a large scale study $(N=10,149)$ as he tested Bernstein's theory. That approach is borne out in the stories of these four very bright graduate students as they work to be very successful in the Canadian university system. Language is the one common challenge that these scholars identify in their transitional stories. It brings to mind an experience that the first author had as a professor at the University of Windsor that related to Newfoundland dialect. Barry Halliwill, a friend of the first author, called and suggested that he should turn on Canadian Broadcasting Corporation (CBC) television to watch a show about fishers from the Southern Shore of Newfoundland. CBC had the transcripts of the conversations written as subtitles, so that the national audience could understand what was being said, because the dialects of the fishers were so thickly Irish. Cable television and globalization are eradicating these beautiful dialects that we were once shy about and of which we are now so proud. Barry appreciated our dialect but he had such a great sense of humour that he could not let the opportunity pass without sharing it.

A second trait that each of these scholars has exhibited is a keen intellect and a prodigious work ethic. Admission to our programs is very competitive and these four students came to MUN with very high academic grades from China and each received academic honours for high achievement in different facets of their previous study. Another positive attribute is the fact that three out of four have opted to complete a thesis as part of their master's program as they all intend to pursue Ph.D. programs. The earliest of the students who is nearing completion of her master's studies has already obtained conditional admission to our Ph.D. program and she already has a well-defined research program outlined.

One practice that is culturally inconsistent with Canadian universities is that of giving supervisors gifts. When students were told that giving gifts was inappropriate, they felt that they were being pushed away and that being friends with their supervisor was not acceptable. After they were reassured that our cultural practices discouraged giving gifts and that in fact it was frowned upon formally, they were more comfortable in their new setting. This was merely another part of their transition to a new culture.

\section{Comparison of Backgrounds}

As this collection of stories was prepared, it was collectively agreed to address a set of common questions in what was written to tease any findings that might be similar. These four graduate students opted to study in Canada, because they felt that their life prospects would be bettered by completing a graduate degree in Canada. Two students knew one other student in the group of four prior to coming to Canada and positively influenced the other student to pursue studies in Canada. The stories presented here are as they were constructed by each student following the first organizational meeting. Three of the students constructed their responses in a story format and one presented his response as answers to the questions that were developed. One student did both - answered the questions and wrote an essay response.

Two of the students work at the university level, one as a department head in a prestigious university high school, and the other is a student. Three of the students studied English as an area of study and were more fluent speakers and writers than the fourth student. After only three semesters, the fourth student has made tremendous progress to the point that she has gained admission to a Ph.D. program at a Canadian university. While language posed the biggest challenge to all four students, they communicated effectively enough to be successful. As their tenure of study continued, their linguistic ability increased tremendously. Both Zhao and $\mathrm{Yu}$ were very comfortable compared to the other two students right from the beginning as the two of them had already experienced a far greater immersion in all forms of communication in English. 
The exchange differential between the Chinese and Canadian currencies tends to cause a financial burden for students undertaking studies in this country. This financial pressure is exacerbated by the economic pressure present in Eastern Newfoundland as a result of the offshore oil industry. Housing prices, apartment rentals, and the cost of nearly every service have caused inflation to living costs to everyone living in that area of the province. These factors have seen double digit increases over the past decade in regular living costs. Thus, what was a really affordable study experience has been made more expensive by cost pressures outside the educational sector. Tuition costs for international graduate students at the study university are the lowest in all of Canada. The low tuition makes the university very competitive from a cost perspective in spite of high costs of living. These pressures were discussed in our meeting as we prepared our paper.

Social adjustment has been difficult for each of the students and for different reasons as they discuss in their papers. Even Toronto is small from a size perspective when compared to the cities these students call home. St. John's, with only about 200,000 people in the metropolitan area, is a whole different experience socially. The dedication of these students to their studies sees them spending most of their waking hours studying and working at personal self-improvement. While there is isolation from their families, time passes quickly as they respond to deadlines and pressures from their courses of studies. Their stories are interesting, different, and reflective of their different backgrounds and their accounts are honest representations of their cultural transitions to a Western society.

A semi-structured set of questions were used to provide a consistency of responses to ensure as complete a picture as possible in limited space permitted by a multiple authored paper. Responses are unaltered to allow the paper to be as authentic and genuine as these new scholars are.

\section{Life Change in My Early 30s-By Dandan Lu}

\section{Losing Balance and Seeking Change}

I had been a diligent person both at study and work. Struggling though the critical competition in Chinese society due to the huge population and accompanying centralized politics and conservative traditional culture, I was successful with many achievements as a student and a worker in the first 30 years of my life. In Xi'an City, a provincial capital and an important center of politics, economics, and culture, I was in a good class level with strong social network, as a result of working at a reputable top high school and working for ruling party at the same time. I achieved much more than most high school teachers who are of a similar age with me and even older than me. I was supported by many students, parents, and colleagues in teaching and in school administration. I can say that in many people's opinions, my life was bright.

However, I felt very unhappy and my mind was unsettled. I was dissatisfied with many affairs in my social and working environment. I felt that there are three factors causing that. First, my marriage was unfulfilling; I felt pressure more when I got home after working hard all day. Since I was unhappy with my ex-husband, had no children, and no one to influence my mood at home but my ex-husband. Unfortunately, the influence was negative for me. A second factor impacting my emotional well-being was too much work pressure that made me feel tired. While I achieved a lot and got significant support, I also undertook more and more responsibilities and accompanying pressure. Third, many social problems raised up associated with the development and transformation of country in China. People are not satisfied with the reality. I was often confused with the problems and tried to consider how to resolve them. As an educator and humanist, I felt that it was my responsibility to inquire as to how this educational rebuilding should respond to social transformation 
and restructuring. However, I did not have the answers and experienced confusion many times.

As a result of these pressures, I felt that I lost the balance in my life. The idea of changing my situation became stronger and stronger in my mind.

\section{Choosing Canada and Preparations to Travel Abroad}

I had valued my career and was interested in personal improvement. After weighing the pros and cons, I decided to study aboard. In my opinion, studying education in another country was a safe and good idea for me, because I would not be far away from my career and when I improved my educational standing, it would be an opportunity to change my life by escaping from a stereotyped environment. After a comprehensive comparison, Canada became my destination because of its reputable educational environment, multi-cultural atmosphere, developed economic foundation, mature democratic situation, and acceptable immigration policy. I received three offers from Canadian universities: the University of Manitoba, Concordia University, and MUN. At last, I decided to attend MUN due to its good reputation and lower tuition. It also had a more moderate local climate compared to other Canadian universities and provinces.

The process of preparation to go to Canada was rough/hard for me. First, I did not take enough English courses before travelling and I had been far from English courses for many years since I graduated from university. Thus, I had to attend some English lessons again in some private institutions of language training. Although I passed the Test of English as a Foreign Language (TOEFL) examination, I knew my real English ability was not good enough. Second, getting visa was a critical step for Chinese students who want to study abroad, especially getting Canadian visa and study permit was more difficult than getting those of America, Australia, New Zealand, and so on. Noticing that some Chinese students failed to get visa and had to delay or give up their study to Canada, I was very careful to follow any specific procedures. Third, sometimes, I had to overcome my contradictory concerns. Sometimes, I second guessed my decision to go abroad, especially when I heard some disagreements from family and friends about my decision to study abroad. Another factor was that I still very enjoyed most aspects of my work.

\section{New Environment and Unprecedented Challenge}

Finally, I started on my trip to Newfoundland after the tough process of passing TOFEL exam, applying to universities, and obtaining a visa. However, the hardest difficulties that I experienced in the process of preparing, became more problematic after I left China. This was the first time that I moved in a new foreign environment by myself in a different language. Based on my humanities background and the work experience in an open school, I was not unfamiliar with Western cultural, political, and social concepts. Therefore, these issues were not the greatest barriers to my living in a Western county. The biggest difficulty, which also continues to be the main source of most of my problems, is the language barrier. As a result, any work that I completed was discounted even though I was actually knowledgeable, culturally aware, and capable of conceptual understandings. Most times, I knew what the case was, but I could not express myself very well. Secondly, I became short on money with no income and not enough funding from university or government. Thirdly, I started to enter into the first period of life that I had to cook by myself which costs me at least two hours per day. Of course, my cooking skill was continuously improving at the same time and rate as my English ability.

After a while, I adapted to the situation that I was always underestimated by others on my intelligence level or general ability level. This new feeling was very different from before, because I was never negatively 
impacted by the expectation of others. I felt very relaxed as the pressure was always positively related to outside expectations.

\section{Good Fortune and Self-Efforts}

I usually meet some good fortune especially when I am in adverse situations. The people in Newfoundland are very friendly, and the professors as well as the staff of the faculty office who I met are all very nice and patient. Many difficulties were resolved through the communication with these kind hearted people. However, the most important person after I registered at MUN has been my supervisor-Dr. Noel Hurley. Dr. Hurley is wise, bright, generous, warm-hearted, and patient. He cares about his students much more than his duties, which is very significant for international students like me. Drawing on his instructions, I overcame the barriers to be successful with my required courses, and after deciding on my thesis topic, I have become excited with my research, especially, as it became more and more clear in my mind about my study life. Dr. Hurley is well versed in academic research with abundant achievements and experience. Being influenced by him in a positive way, I was lucky to avoid many troubles which I might meet during my study process.

I created a social network (named QQ group), in which members were all the students who were going to MUN, on a website before I came to Canada. I benefitted from it through sharing our experience and knowledge among our new students in the online group. I did not think it would become so helpful for so many Chinese students at MUN. Now, it has become the biggest QQ group which influences Chinese people most widely in Newfoundland. More and more Chinese students and new immigrations obtain information and help from it. Also, it became a significant student society, for example, one vice-president of the Graduate Student Union got a lot of supporters from it when he run for his position.

I am good at communication due to my outgoing personality. I have tried to talk and know more people in Newfoundland. More friends means more information that has helped me have been accepted gradually by Newfoundland. In fact, people are similar in their nature whatever their ethnicities or nationalities. In this social world constituted by humans, those who can get supports from others can get better opportunities to live.

\section{New Goals and New Impetus}

I think my transition has been successful; I also believe that I have benefitted from the inclusive society of Canada, the flexible educational system, the generous professors, the instrumental departments of the university, the personal efforts as well as positive attitudes.

Now, I enjoy my research and I feel that I have adapted to life in Newfoundland. I tried to get a part-time job to reduce my financial pressure and to engage in more communication with people. A couple days ago, I was elected President of a newly developed graduate student association with great support from some friends, which really made me feel happy and moved with these valuable friendships. I also received notification of acceptance to study a Ph.D. at MUN which will be supervised by Dr. Hurley. I want to increase my involvement in student affairs and try to create more communication between China and Canada in educational domain.

Anyway, I want to express my cordial gratitude to the people around me. Just your encouragement and support made me being brave enough to face the challenges of the future in Newfoundland and Canada.

The following section presents Dandan Lu's responses to the questions that were used to lend consistency for the students in the telling of their own personal stories.

1. Why did you apply to study in Canada? 
First, to escape from the struggles related to personal affairs. Since my marriage made me feel unhappy, and I did not know how to resolve that problem, I decided to go to a new environment to transfer my attention from the unhappy life.

Second, the need of professional development requires me to enlarge my insights. In order to be a more excellent teacher, I should know more about the information of teaching and learning in other countries to compare our own situations, and try to refine my own teaching theories and practices.

Third, seeking for better understanding to contribute the transformational society. China is in the period of transition, and the social changes have caused the reform or restructuring of education. As an educator, I am responsible to explore and devote for the construction of the balanced relationship between education and society.

2. Where else did you apply?

Besides MUN, I applied and was accepted at the University of Manitoba and Concordia University.

3. What was the biggest difficulty you experienced in coming here?

Among countless difficulties, the language problem has been the biggest one. Most times, I know what the case is, but I cannot express myself as well as I would like. It often distracts from my study and personal communication even though I am actually knowledgeable and culturally aware of what is being discussed.

4. How prepared were you to come to Canada from a linguistic, social, cultural, political, and financial perspective?

Based on my humanities background and the work experience in an open school, I was not unfamiliar with Western cultural, political, and social concepts. Since I did not take enough English courses to develop a good English ability when I studied in schools and universities, I chose to go to language training institutes to adapt the second language requirements. Due to the good salary of my former job, I saved some money which can afford the basic financial challenge to study in Canada.

5. How accommodating and helpful were university officials? Government officials? Others?

There is a department called the International Student Advising (ISA) office in MUN. It supplied airport pickup and basic accommodation instructions when I first time came here. However, I think the most help which I got was from my supervisor (professor) and one group of online communication which I created by myself, during the first two semesters after coming here. My supervisor is very patient and caring. I was lucky to get a lot of instructions and suggestions including academic and non-academic domains from him. The network group which I established has become the most influenced online community of Chinese people in Newfoundland. I did benefit from it while it benefited others at the same time. At first, new students discussed all kinds of situations that they met in that group, and invited a few old students to join them and gave them related advice. Because they met similar difficulties and challenges, the discussing among this culture-sharing group was very significant. Therefore, it is very popular among Chinese students as well as some Chinese people in Newfoundland. I also benefitted from my faculty after I learned how to communicate with faculty office well.

6. Did anyone serve as a liaison during your move here?

No.

7. Do you feel that your transition has been successful?

I think it was successful. I had good fortune with many things, I think.

8. What or who has helped you most during your transition? 
My supervisor, undoubtedly, has been the most significant person with special emphasis on academics.

His expertise in communication helped me adapt and make a successful transition, although my English was not good as what I thought it was.

9. Are costs to come and study here too prohibitive for most Chinese university graduates?

I think they are. Six Chinese Yuan are equal one Canadian Dollar, so the tuition of Canadian universities means six times tuition of Chinese universities for Chinese families and students.

10. Has the cultural, social, linguistic, political, and economic differences been more or less than you expected? You might like to examine each of these aspects individually.

What I found was kind of what I expected. But I do not think there are many more differences than what I expected before I came. Since China is open enough currently, many Chinese people are familiar with Western cultural, political, and economic situations very well.

11. What has been your greatest help?

I think the funding from university and the help from professors are two greatest helps.

12. What has been your greatest hindrance?

The funding is still not enough for me to live in Canada, so I have to be cheap for my life. I think it is my greatest hindrance.

13. What has been your most pleasant surprise?

I received widespread support to become the first president of the International Student Society of Education, which was my most pleasant surprise. I did not think they supported me and trusted me so much.

14. What has been your biggest disappointment?

It is not easy for me to get a part-time job to reduce my financial pressure here, which has been my biggest disappointment. I tried to look for some part-time positions, however, it has only been within the past week that I was able to acquire a job.

15. What should the university do to make the transition of students from China easier?

I want to say the functions of ISA office for new international students are good already, and I know many students appreciate what they (ISA) did. However, I still have a few suggestions for the university.

First, the university can encourage professors or supervisors to care about students both on academic and non-academic level. I think not many students are as lucky as me to meet so many responsible supervisors and other professors, especially my supervisor.

Second, the university can encourage the former (and more senior) students to mentor new students. This kind of encouragement should be more attractive than before, for former students who would like to help new students, such as awarding funding for the mentor students. I think the help from the mentor (student) to mentee (new student) would be more specific and flexible than the help from departments of university.

Third, the university can advocate for more local families to become involved with the transition for international students than the current situation. The involvement of local families would help international students become familiar with local issues and Western situations more deeply and widely than other processes.

16. What would you recommend to other Chinese university graduates to do before coming to Canada?

Language training is the primary task to finish. Second, being brave is very important for any international students. In fact, most difficulties can be resolved by a brave student! 


\section{Xin Wang's Canadian Transition}

In September of 2012, I first came to St John's as an international student. I was so excited to be headed to Canada and looked forward to studying at MUN. Before I came here, I made great efforts to increase the likelihood of success in my studying abroad. I started to learn English from the age of five and I have spent a lot of time and effort trying to increase my fluency. It has been a hard and long journey for me. During four years of undergraduate studies in English, I studied hard to make sure that all of my academic records were characterized with excellence. I always ranked in the top 5 among 48 students in my major with a grade-point average (GPA) of 3.55/4.0 and I was awarded a scholarship from the university every year. In my spare time, on behalf of my university, I was responsible to receive and assist professors from various universities and colleges abroad. I also participated in the College of Arts and Science Translation Team and served as an Olympic City Volunteer in the 2008 Beijing Olympic Games. My parents strongly encouraged me to consider studying abroad as a part of my graduate school experiences. They hoped that I could study in the province of Alberta, because my aunt earned her Ph.D. at the University of Alberta and has been living in Edmonton for a long time. My parents have a pretty good relationship with my aunt and they have always been incredibly supportive of me. I really appreciate that my parents financially support my tuition fees and living expenses abroad. After choosing where I wanted to study, I applied to the Educational Leadership Studies Program at MUN and applied to the University of Alberta. I am also very interested in studying in Ontario, because big city life is full of enjoyment. I have grown up in China's capital, Beijing, and I am quite familiar with big city life. But after carefully reading the descriptions of courses offered at Brock University and MUN, I chose MUN for studying Educational Administration and decided to study in St. John's. Before I came to Canada, I got in touch with some Chinese students in MUN through online chat software and joined their Facebook group for new international students. I made some new friends in a new city and they also helped me find off-campus accommodation before I came to St. John's.

However, I felt depressed nearly every day when I first came to St. John's, the capital and largest city in Newfoundland. I felt uncomfortable and unhappy living in a small town and I could not make this new city feel like home. In St. John's, there are quite a few shopping malls and I have experienced a lot of participation in social activities, such as swimming at any time and visiting interesting places. I also had a hard time understanding the Newfoundland accent and I often did not understand when native English speakers spoke too fast. I also worried about my career and future, because job opportunities are not abundant in a small city.

But the people of St. John's are very friendly and welcoming. My neighbor usually helps us clear the snow around our house and shovel our driveway. My faculty adviser who is my favorite professor in MUN wants me to succeed and is always willing to take time to answer my own questions. Officers in the ISA office help me learn about registering for courses, academic options, required health insurance, and working in Canada. At the beginning of my graduate career, I always encountered various learning problems across all curriculum areas. I was afraid to write a term paper and I usually spent a large amount of time writing academic papers. Sometimes, I did not understand the educational administration writings and was unable to improve my knowledge of English. But my faculty adviser constantly gives me valuable suggestions for improving my study skills and guides me to have a better idea of my future career path. My adviser who is also teaching graduate courses usually meets with me to discuss my course preparation and the questions about my assignments. He helps me edit my papers before submitting them for peer review and explains English grammar rules for me. My adviser 
also wrote a letter of recommendation for me and encouraged me to apply the Bachelor of Education (Intermediate/Secondary) conjoint with the Diploma in Technology Education Program at MUN. With his help, I also applied for a graduate assistantship in almost every semester in order to gain work experience in the educational field and lighten the financial burden on my parents. My parents are pouring most of their savings into sending me to study in Canada, because one Canadian Dollar is the equivalent of the amount of money 5.7 Chinese Yuan. The high price of books or textbooks often cost me as much as a month's rent and the cost of food is also very expensive in Canada.

During one and a half years of full-time study in Canada, I have improved my academic performance and have made the transition from dependent childhood to independent adulthood. I have developed good study habits and have learned important life skills in order to be successful at living independently. I can arrange my own study time properly. I am no longer afraid to overcome the difficulties in my study and to learn new things to further develop my ability. I have also greatly improved my English writing skills and I have gotten over my fear of writing a long research paper. The main reason that I have made good progress in writing is because I go to the Writing Center at MUN every week to get assistance writing my assignments and term papers. I am very happy that my writing tutor treats me like her close friend and encourages me to love writing in English. What is more, I am so extremely excited that I have been admitted to the Secondary Education Program. With the encouragement of my adviser, I will have the opportunity to complete a Bachelor of Education Degree at MUN and thereby obtain a valid license to teach in Canada. Additionally, I have to say that studying in Canada is not always easy. Chinese students must expend enormous amounts of effort to improve their English skills and their academic performance. They should also master solid and basic professional knowledge before studying at a Canadian university. In order to get involved in the social life of Canada, Chinese students need to learn to expand their social circle and their horizon of social activities. What is more important is that learning to live independently and learning reasonable arrangement of study time will help Chinese students succeed in Canada.

\section{Personal Opinions About Chinese Students Transitional Experiences-By Hailiang Zhao}

1. Why did you apply to study in Canada?

The high quality of Canada's education has gained its reputation across the world. Before applying for a university, I compared the courses offered, the tuition, the living cost, the job opportunities, and the immigration policies of several universities and different countries, and I decided that Canadian universities are of the best value.

2. Where else did you apply?

Although Canadian universities are featured with best value as a whole, there are some differences between different universities. As a university staff with 15 -year work experience, I value more on whether the courses offered are suitable for me than on the position on the ranking list. After studying the information of several Canadian universities, I narrowed my choice to two universities - the University of Manitoba and MUN. And finally, I was admitted by MUN.

3. What was the biggest difficulty you experienced in coming here?

I would say that course learning is still my biggest difficulty. Due to the learning habit formed in the past years, I have been used to getting instructions from teachers and instructors about what I should do. However, I 
have to adjust myself to the new learning systems in Canada. Independence is quite important here, and students should schedule their time by themselves and think independently. I think this is challenging not only to me, but also to any Chinese student who is studying in Canada.

4. How prepared were you to come to Canada from a linguistic, social, cultural, political, and financial perspective?

I made my plan to study in Canada two years ago. The moment I made the decision, I started to search the requirements of English ability, finance, and academics. I took the International English Language Testing System (IELTS) and TOEFL tests, deposited enough money in my bank account, and translated one of my published articles as a sample writing to submit to the admission office of MUN. Fortunately, all of these preparations were done before my application.

I have ever studied at two universities (the University of Iowa and Drake University, both located in the State of Iowa) in the United States (U.S.) for totally a year. Canada has quite similar linguistic, social, cultural, and political settings with the U.S., so my life experience in the U.S. has helped me understand the Canadian society. On the other hand, in my daily work at my home university, I had long connection with some Canadian students, who have ever introduced their countries to me, so I have obtained a rough idea about Canada. Besides, to make my transition proceed easily, I searched for some information about St. John's where MUN is located. The information has helped me learn more about the economy, weather, transportation, natural environment, etc., of St. John's.

Before arriving at MUN, I contacted the departments providing services to the international students, such as ISA. I obtained information about housing, airport picking up, and other information. These made me feel safe before going to a new place.

5. How accommodating and helpful were university officials? Government officials? Others?

From the very beginning of my study at MUN, the university officials and teachers have been offering me a great help in registration, course selection, fellowship application, and course study. Whenever I sent email to the teachers or the staff asking for help, they gave me feedback very soon. In most of the time, my problems were solved. Even if the teachers or staff could not directly answer my questions, they told me whom to refer to.

Thanks to the support of the teachers and staff, I have never met any real difficulties so far.

6. Did anyone serve as a liaison during your move here?

There was no appointed liaison. However, I did get instructions from several staff before moving to MUN. For example, I kept contacting Ms. Tina Hunt for study issue, and a staff of ISA for airport picking up. In addition, a Chinese student, Ms. Dandan Lu, gave me quite a lot information about life and study at MUN.

7. Do you feel that your transition has been successful?

I think my transition has been successful.

8. What or who has helped you most during your transition?

My advisor, Dr. Noel Hurley, and the Chinese student, Ms. Dandan Lu, are the two persons who helped me most during my transition.

9. Are costs to come and study here too prohibitive for most Chinese university graduates?

Cost is really a big concern for most Chinese students. However, the tuition fee of MUN is much lower than most Canadian universities, which makes MUN fairly competitive in attracting Chinese students.

10. Has the cultural, social, linguistic, political, and economic differences been more or less than you expected? You might like to examine each of these aspects individually. 
Thanks to the prior experience and preparation, I have not encountered any differences from what I expected.

11. What has been your greatest help?

An effective communication has been proved extremely helpful in my transition. Any time when I had questions, I emailed or made phone calls to the teachers or staff, telling them what help I needed, what confused me, and they were all very happy to help me.

12. What has been your greatest hindrance?

My transition has been very smooth, and I have not had any real difficulties so far.

13. What has been your most pleasant surprise?

What surprised me most is that the MUN educational system is quite flexible. I was originally admitted on the course route, but I was told I could apply for a change to thesis route, which was what I had hoped to do. With the support of my advisor and the administration staff, I changed to thesis route successfully.

14. What has been your biggest disappointment?

What disappointed me most is that I did not have a satisfactory result in one course study in the first semester for I did not well distribute my time in study and work for my home university.

15. What should the university do to make the transition of students from China easier?

I suggest a Chinese student service center be established to issue information about or provide service in housing, registration procedure, banking, and other issues closely related to the transition of the new Chinese students. As far as I know, due to the reasons in language inefficiency or learning habit, some Chinese students at MUN never communicated with their teachers. Some even do not know that they have advisors. Under such condition, I think this organ could offer more direct, explicit, and systematic service to the new Chinese students than any other organs. Currently, there is an online group of Chinese students at MUN, but the new students will be given directions only when they raise questions. Rather than support the transition of the new students, this group focuses on chatting.

16. What would you recommend to other Chinese university graduates to do before coming to Canada?

I would firstly suggest the Chinese graduates to master English speaking, listening, reading, and writing skills, so an effective communication could be conducted either for daily life or for academic purpose with professors and staff. On the other hand, a satisfactory course learning needs students have a good command of English, especially in reading and writing.

Secondly, the students who hope to study in Canada should have a clear study purpose and an practical study plan. Being admitted to a Canadian university is just a beginning of the story. Many Chinese students who are not used to independent study get lost when nobody drives them to learn.

Thirdly, before going to the new country, try to find useful information as much as possible, in academic studies, daily life, and social culture. The best resource for academic information is the university website. Other resources could be the current students available online, for example, Facebook or QQ online chatting group (a Chinese online chatting software). The information may help the Chinese students have a smooth transition.

\section{Bronze Sparrow Terrace, the Story of a Man and Others-By Peng Yu}

"Your life story would not make a good book. Don't even try."

Fran Lebowitz 


\section{"Little Red Book" in Heart}

In 1915, a crowd of students at Peking University was waiting for their instructor of English poem. Suddenly, the whole class burst out laughing when a tall, slightly Western looking man with a brown queue entered gracefully. The man was dressed in a black gown and a little cap of the Tsing Dynasty which had been overthrown for four years. The instructor took his queue in his hands and said, "You see that I wear a queue, but your queues are all in your hearts." When the students heard this, they were terrified, and fear fell upon them. ${ }^{1}$

The instructor named Ku Hongming (幸鴻銘) was born in Malaysia, the son of a Malaysian Chinese and his Portuguese wife. ${ }^{2}$ He was brought to Scotland at the age of 10 by his foster-father, and acquired his formal education in the United Kingdom, Germany, and France (Cf. Müller, 2013). If such a Europeanized man had not cut his queue in his whole life, how could I get rid of the queue in my heart? Even worse, there is also a "Little Red Book" in my heart, namely, the influence of the Cultural Revolution.

During the year before my coming to Canada, I had been deeply involved in the conflicts among the leaders of School of Foreign Languages, MY University. The Cultural Revolution happened again! My colleagues divided into hostile groups, and friends never trusted each other. I had to take sides, as I was the Acting Director of the Department of English and one of the members of the school administrative committee in name. I posted comments in the school listserv/discussion forum to criticize the newly appointed dean who specialized in Mechanical Engineering and used to be my friend. At the beginning, I absolutely believed that my conduct was compelled and completely out of righteousness; however, later I felt that actually I was happy to do that. Unexpected fear overwhelmed me, as I felt that the curse of the "Little Red Book" was so strong on me. Please forgive my taking the liberty to ask just out of curiosity, "Do you happen to have the Little Red Book in your heart?"

\section{A Successful Escape}

I had been depressed all the time during the "Cultural Revolution" at my school, and decided to get away from the undesirable environment. To better understand my miserable life, I applied to Yale Divinity School for the purpose of studying theology. Unfortunately, I got the conventional feedback that "the applicant pool was exceptionally strong this year, thus making our decisions very difficult." When I was wallowing in the valley of despair, Mr. H, a colleague and friend, told me that he was offered a position to pursue his Master Degree in Education in Educational Leadership at MUN when we had lunch together in the university cafeteria. After I went through all the options of Canadian universities, there was only one choice remaining. I wanted to attend MUN with Mr. H.

Before my leave, all the school knew. Some colleagues considered that I was either crazy or stupid to study abroad in my early 40s, and I actually quite hesitated about the decision at that time, because it would follow me then and into my future. Whenever a colleague congratulated me, I would repeat that "I run away with my tail between my legs." However, when Dr. Z passed me by, he blinked and said, "It's a successful escape!"

Yes, indeed it was. One autumn day in St. John's, Mr. H took a photo of me on the top of Signal Hill, when the sea was so deep and sky so blue. I posted the photo on my Facebook Timeline, and entitled it as "A

${ }^{1}$ Dramatized from the description by William Somerset Maugham, and other anecdotes of Mr. Ku Hongming (Cf. Maugham, 1922).

${ }^{2}$ Zhou Zuoren reported this (Cf. Li, 2002). 
Successful Escape!” Right beside that English phrase, there was a Chinese annotation “海闊天空” (Between the Sky and Sea), which signified the space in which I would prosper.

\section{The Scholars}

Besides the help I obtained from Mr. H, three Canadian scholars supported me most in St. John's, Newfoundland.

Dr. Walter Okshevsky. The Faculty of Education appointed Dr. Walter Okshevsky as my mentor ${ }^{3}$ at MUN before I came here. I think his responsibility is somewhat like the "personal tutor" in Oxford/Cambridge system, and it has proved invaluable. When I first met this tall, intelligent philosopher, I told him that many people thought that I was quite successful, but they failed to penetrate the superficial achievement into the nature of my life. The education I received from the University of Liverpool and Trinity College Dublin (TCD) had undermined my future in China, because the European education made it hard for me to readjust myself to the social context in my own country. I came to the conclusion that I was a loser in life. He said calmly, "Welcome to the club." Then he asked, "Do you play table tennis?" I answered, "Sure, when I was six years old, I was trained by my elder brother. He used to be the coach of Russian Junior National Team." Since then, we play table tennis almost every week, and occasionally I practise my Russian on him. Sometimes, when we are not busy, we sit in the University Centre arguing about religion, creation/evolution, paleoanthropology, and language acquisition. I am quite amazed to find that Dr. Okshevsky shares so many similar weird interests with me. To pretend not being a shallow person before him, I read some history about Greek plays. Interestingly, I found that the plots of ancient Greek tragedies and comedies are as the same as, or even more sophisticated than those of Shakespeare's most distinctive works.

The most pleasant surprise to me is the popularity of table tennis in Newfoundland. Before I came here, I even left my paddle at home in China. While I was playing the game, many people watched. One day, Adam Drover, the provincial table tennis champion of Newfoundland and Labrador (NL), came up to me and played with me for a while. We agreed to play again next time when he would carry his own paddle with him.

Dr. Noel Hurley. Dr. Noel Hurley was my course instructor for Educational Policy: Theory and Practice. He is sagacious, helpful, caring, and accommodating, and his experience as school principal and superintendent is precious to me.

Dr. Hurley had made the course so practical to students. When I was doing my first assignment, I felt so frustrated. It was about the amalgamation of school boards in NL. I had to read a lot about the three amalgamations in the previous 15 years, the eradication of denominational system, and watched almost all the videos related to the nearest amalgamation. In January 2014, I attended my neighbor John's 90th birthday party. Since John retired as a school principal, his house was congregated with retired teachers and principals that day. I felt so proud to see the astonishment in people's faces when I was criticizing the recent amalgamation together with them. For my second assignment, I had to refer to some school policies to compose a policy actually by myself. The process of making a policy can be quite pragmatic for my future work in a school setting. The term paper assisted me in gaining some understanding about comparative education. To conduct the study, I accessed the data provided by the Organisation for Economic Cooperation and Development (OECD) and investigated the results of 2012 Programme for International Student Assessment (PISA) tests.

\footnotetext{
3 The word "adviser" is commonly used in the North American educational system. But the traditional Latin word "mentor" is used here to show more respect.
} 
The course, indeed, is very difficult, especially for an international student like me. But after completing it, I have acquired rich knowledge about education in North America. Dr. Hurley's comments were always insightful and direct, and his constant encouragement made me more and more confident about myself.

Dr. Bonaventure Fagan. Spiritual life is utmost crucial to me. I attend Latin mass in St. Pius X, as the Latin language and ritual make me feel so close to the Martyr Saints of China. However, as I was not brought up in a Catholic tradition, I invariably need intellectuals to help me strengthen my faith. Mrs. Rose Goodstadt, JP (顧楊彥慈太平紳士), former Director of Social Welfare in colonial Hong Kong, and Fr. Paul Han (韓清平 神父), Father Provincial (China) of Divine Word, had sponsored me in Ireland and China respectively. In Canada, Dr. Fagan acts as my spiritual facilitator.

Dr. Fagan retired as an official of the former Roman Catholic school board in Newfoundland, and he had been educated in a seminary school before he decided to specialize in education. Every week, I call on him with all my unorthodox questions, he always lends me a sympathetic ear and offers me his personal understandings and explanations toward our faith.

\section{The Isolation}

There is a time for everything, a time to embrace and a time to refrain from embracing, a time to laugh, and a time to weep. ${ }^{4}$ Sometimes, I feel exceedingly lonely and isolated. There is constant pressure from my academic study, so I can hardly find time to enjoy Canadian life. Besides, my unique educational background and individual perceptions toward Chinese history and culture impose restrictions on my blending in the Chinese student community in St. John's. Most importantly, I miss my aged parents, beloved wife, and cute son in China.

One midnight, while I was walking home in the bone-chilling cold and blinding snow, I said to myself somberly again and again in Irish: "An bhfuil tusa ag labhairt liomsa?" (“Are you talking to me?")

\section{The Canadians}

Undoubtedly, there are cultural, social, linguistic, political, and economic differences between Canada and China. Nevertheless, if we emphasize these differences, we will lose the power and opportunities for interaction. The Canadians are very, very friendly, and all the people I meet try their best to make me feel at home.

Last December, three families invited me to have Christmas dinners in their houses, which made me quite hesitant to decline any of them. To express my gratitude, I bought three bottles of Italian wine for those families.

A month ago, I went to the city centre for sightseeing. As soon as I walked into a United Church with a Victorian outlook in Gower Street, everyone in the church immediately recognized that I was a Catholic, as I habitually knelt down when I entered the hall with the Jesuit ritual. Prof. Roy West and his wife Dr. Pat West came over to talk with me. Before I departed, they invited me to have dinner with them. I was a little bit nervous and murmured, "But I am a Roman Catholic." Pat laughed and replied, "I don’t care."

Brady Kelly and Jenna Mandaville, my roommates, are quite warm-hearted. Now and again, they ask me to drink beer together, and listen to Newfoundland Irish music with them. In terms of English pronunciation, I always trust Jenna, while Brady's method of teaching oral English seems quite efficient. He asks me to drink

\footnotetext{
4 Adapted from "A Time for Everything" (Ecclesiastes 3).

5 A phrase that recurs throughout the film Yu Ming Is Ainm Dom (My Name Is Yu Ming), which tells the tale of a Chinese young man who has learned to speak fluent Irish, but cannot be understood when he visits Ireland and feels extremely isolated.
} 
beer, and my oral English becomes quite fluent after drinking just one bottle of beer. Brady is great, as he can shotgun and beer bong very fast. I will definitely introduce those beer drinking techniques to China. I totally agree with Plato that "he was a wise man who invented beer." When I sang "Amhrán na bhFiann" (The Soldiers' Song) ${ }^{6}$ in Irish, Brady, being of Irish decedent, became so surprised to know that Irish was a language. And when I talked about the history of Newfoundland, Jenna was so glad to help me to pronounce "Shanawdithit," the name of the last known Beothuk woman.

$\mathrm{Ku}$ (1915) claimed that:

In order to estimate the value of a civilisation, it seems to me, the question we must finally ask is not what great cities, what magnificent houses, what fine roads it has built and is able to build; ... The question we must ask is what type of humanity, what kind of men and women it has been able to produce. (p. 1)

Canada is, I can say without any hesitation, a model country in producing her chivalrous sons and graceful daughters.

The other day, I opened the door, and saw the hills veiled with glittering and translucent snow. I smiled, and chanted, "Мороз и солнце; день чудесный!” (Snow, frost and sunshine; lovely morning!) ${ }^{7}$

\section{Barrier of the Language}

I am totally an "underdog" in English learning. In Canada, it has still been my greatest hindrance to communicate properly and elegantly with the language, so I started to recollect my previous experiences for the purpose of finding a way to perfect my academic speaking and writing.

In January 2010, I dropped in on Mrs. Rose Goodstadt with my son, Charles (于歌子) in Dublin. When I consulted her about improving my son's English. She said, "You should read English for Charles every day." Abruptly, she changed her mind and added, “Oh, no. Don't speak to him in English, because your English is very bad." It was the first time that someone was so honest to me about my English level. Then, I told her that I had been working very hard to improve my English. It took me almost two years to try to recite the Oxford Dictionary, and I got extremely high scores in both IELTS and TOEFL tests. But I still can hardly use my English freely in speaking and writing as native speakers. Then she asked, "Do you read a book a day?"

After that meeting, I read English books every day, and found that my oral and written English had not evidently improved. Then I realized that her suggestion was not really appropriate to me. She was born in an affluent family. Her father was a friend of Guo Moruo (郭沫若), while His Eminence Cardinal Ignatius Kung Pin-Mei (龍品梅樞機主教) was a relative of her mother's family, and actually the Cardinal passed away in her family house in the U.S.. When she was young, she received her formal education in English speaking Catholic schools in Hong Kong. She studied English literature at Oxford University, and her husband, Mr. Leo Goodstadt (顧汝德先生), former chief policy adviser of Baron Patten of Barnes (彭定康男爵), was British. Obviously, English speaking and writing may have never been a problem for her.

After the failure of my desperate attempt to improve my English, I had a dinner with Prof. David Singleton, my previous mentor at TCD in March, 2010. I told him that the process of language acquisition was so mysterious and far beyond my perception, so I would become a Roman Catholic. David had been the staunchest of opponents of the critical period in language acquisition for almost his entire career, however, he told me that he was also not quite certain about his previous theories now, and some of his ideas had actually

\footnotetext{
${ }^{6}$ Irish national anthem.

7 The first line of Pushkin's "Winter Morning."
} 
changed with age. Professor David Singleton, brought up as a Roman Catholic, became an agnostic after my going back to China.

In Canada, when I was collating my previous e-mails, I found a reply dated on Christmas Eve in 2009 from Prof. Qian Jiaoru (錢佼汝教授) in answering my question whether it is true that the oral English of his uncle Mr. Qian Zhongshu (錢鐘書先生) is better than many educated British people. I met Prof. Qian in Shanghai in late November, 2008, when I was attending a training programme organized by the College English Test (CET) Testing Committee for IBT-CET test designers. Prof. Qian, one of the senior scholars responsible for commenting on and revising our work, was a sapient and extremely handsome gentleman with courtly manner. He told me in the e-mail that his uncle communicated with him only in Wuxi dialect, so it was impossible to evaluate Mr. Qian Zhongshu's oral English. But he agreed with me that it was difficult for non-native English speakers to use the language as adroitly as their educated native counterparts, as non-native speakers have deficiencies in the cultural context. He further pointed out that the only exception is that people who were brought abroad when very young, and they actually should not be considered as non-native speakers of the target language.

Prof. Qian's e-mail took me back to Ku Hongming, who was brought to Scotland before puberty. Ku was well known for his rote learning of the Bible, Shakespeare's works, Paradise Lost, Faust in German, and classics in Latin and Greek. He suggested his students recite one book in English to build a solid base for further improvement. Personally, I believe that rote learning should not be criticized, as musicians memorize the notes by rote, and actors rehearse their lines again and again so that they can perform more expressively. The communicative approach is inefficient for me, as I feel that the language input is still insufficient although I have been living abroad for many times and many years. I remembered that I could use almost all the vocabulary and phrases in the high school textbooks in China, just because I had memorized all those books. However, $\mathrm{Ku}$ did not tell me which book to recite so that I can speak and write elegantly. Is there a short book which contains the basic elements of culture, English structures, and necessary vocabulary for daily and academic communication?

I strongly believe that the Gospel of St. Luke (New King James Version) can serve as a very good short book for rote learning. First, the Western civilization is basically a Christian civilization, and the book tells about the whole life of Jesus Christ and his words. Second, the text is not long, which contains 26,104 words. There are 2,533 different words used in the text, and most of them are frequently used in daily and academic speaking. Third, the stories in it are attractive. Besides those philosophical parables Jesus told, the plots in its Chapters 23 and 24 are so dramatic. St. Luke was a master of Greek language, and he was influenced by both Jewish and Greek culture. Chapter 23 can be regarded as a heartrending tragedy; however, when people are in deep sorrow, Chapter 24 eventually transformed the whole book into an exalting comedy. Fourth, as we all know, King James Bible and Dr. Samuel Johnson's Dictionary were momentous in the formation of modern English Language. The language in King James Version is easy to comprehend, as one of James' instructions was to keep the new translation familiar to its listeners and readers. Its word choice is elegant. In 1611, the 47 scholars, who worked in six committees, two based in each of the University of Oxford, Cambridge, and Westminster, had discussions in Latin on how to choose words to make the translation sound more solemn. To update the vocabulary and grammar of the King James Version, 130 scholars had been involved into the New King James Version translation project since 1975, and more than 600 actors contributed to create its audiobook version with movie-quality sound effects: "The Word of Promise." These actors "perform" the 
words instead of just reading them from the Bible. Personally, I think, the audiobook version is quite beneficial for my accent reduction.

Christi crux est mea lux! (The cross of Christ is my light!)

\section{Suggestions for Newcomers}

My suggestions for Chinese university graduates to do before and after coming to Canada are as follows.

Study the history. I believe that both Chinese and Canadian history should be studied. For my part, I think the history we learned in China has been intentionally distorted for political purposes. It is essential for Chinese students to know our own history and culture, and The Cambridge History of China is worth reading. And fortunately, the Chinese version of it can be bought in mainland China. Only when our people know our history, can we be more liberal to other civilizations and tolerant to different beliefs. For getting some information about Canadian history, I recommend to watch Canada: A People's History, which is a 17-episode documentary television series on the history of Canada. If we gain some knowledge of Canadian history, it will be easy for us to understand the characters of the people and why they emphasize the values around democracy, justice, equity, and inclusion.

Embrace the culture. Canada is a beautiful country with rich cultures. Lots of travel is highly recommended. The destinations may not only be Toronto and Vancouver, for camping in the mountains or talking to aboriginal Canadians can be more exhilarating.

In choosing accommodations, I suggest Chinese students choose to live with Canadian people, so that they can learn from each other. They should also think about joining a student community/society to do some voluntary work, and it is of vital importance to speak English in public areas.

It is advisable that Chinese students read a few classical works in English. Justin Trudeau's ${ }^{8}$ eulogy for his father is the most glamorous and expressive funeral eulogy I have ever heard; however, I would have not understood its true meaning, if I had not read Julius Caesar.

Dream big dreams. When I was asked about my plan for the future, I told my friends that I hoped to revive Jesuit education in Xianxian Diocese (獻縣天主教教區) in China. My friends laughed and were astonished, and could not understand my intention to promote Roman Catholic education in a communist country. My reply was laconic, "Because you cannot understand."

If nobody insists on the values of righteousness, equity, and democracy, how can positive changes be effected in our educational system? If nobody cares those rural children and Acquired Immune Deficiency Syndrome (AIDS) orphans from Catholic families who lack opportunities in receiving a good education, how can the lives of those valuable people be genuinely improved? Albert Einstein was right in saying that "only a life lived for others is a life worthwhile."

\section{Conclusion}

It can be seen that each of these graduate students come from very different backgrounds and have unique personal characteristics from an educational, social, and philosophical perspective. If one analyzes the pieces critically, it is possible to discern differing levels of linguistic ability and writing comfort in English. In their responses to the research questions that guided their written articles, each student commented on the cultural and linguistic challenges that they faced. To an extent greater than one would like to think, their transitions

${ }^{8}$ Canadian politician and the leader of the Liberal Party of Canada, he is now our Prime Minister. 
were likely more challenged than they ought to have been. Their responses identify a real need for institutionalized programs to formally assist new students during the first year of their studies in Canada. This would go a long way to easing the transitional difficulties that each experienced.

A second observation that can be inferred from the written accounts is the amount of pre-planning that each student undertook from a financial perspective. Each had arranged adequate financial resources to allow them to subsist as they completed their graduate programs in a new Western society. While they would be considered well in Chinese society, the exchange rate alone made their financial circumstances much more challenged than if they had chosen to complete their graduate degrees in China. Each student stated in interviews conducted by the first author to gain additional understanding of their written work, that the degree from a recognized Western university had great personal value for them within the Chinese educational systems - primary, secondary, and tertiary. Thus, while obtaining of the Western degree comes at a great personal cost in terms of additional financial needs, experience of isolation from their own culture, separation from family, and linguistic frustration, each graduate student expressed overall satisfaction with their choice of the Canadian university as a place to study.

Finally, Hailiang Zhao's advice to prospective students who wish to study in a foreign university was quoted as a valid finding of this transitional comparison. He said:

Firstly, Chinese graduates should master English speaking, listening, reading, and writing skills, so an effective communication could be conducted either for daily life or for academic purposes with professors and staff. On the other hand, a satisfactory course learning needs students have a good command of English, especially in reading and writing.

Secondly, the students who hope to study in Canada should have a clear study purpose and an practical study plan. Being admitted to a Canadian university is just a beginning of the story. Many Chinese students who are not used to independent study get lost when nobody drives them to learn.

Thirdly, before going to a new country, try to find useful information as much as possible, in academic studies, daily life, and social culture. The best resource for academic information is the Website. Other resources could be the current students available online, for example, Facebook or QQ online chatting group (a Chinese online chatting software). The information may help the Chinese students have a smooth transition.

His sage advice represents a keen observation as a summary finding of the quest to identify solutions to the transitional difficulties experienced by Chinese university students as they pursue tertiary (postsecondary) studies abroad. As a concluding note, each of these four university students has made the difficult transition very effectively and each has grown tremendously from a scholarly, linguistic, and research point of view.

\section{References}

Hurley, N. P. (2002). How you speak determines how you learn: Resource allocation and student achievement. New York, N.Y.: Edwin Mellen Publishers.

Ku, H. M. (1915). Chunqiu dayi (The spirit of Chinese people). Peking: Peking Daily News.

Li, Y. G. (2002). Kuangshi Guaijie-Gu Hongming Biezhuan (Crazy scholar and strange genius: An unofficial biography of Gu Hongming). Peking: People's Literature Publishing House.

Maugham, W. (1922). On a Chinese screen. London, U.K.: Heinemann.

Müller, G. (2013). Gu Hongming (1857-1928) and China's defense against the occident. Heidelberg: University of Heidelberg.

Suzuki, D., \& Taylor, D. (2009). The big picture: Reflections on science, humanity, and a quickly changing planet. Vancouver: Greystone Books. 